\title{
Cancer-testis antigen HCA587/MAGEC2 interacts with the general transcription coactivator TAF9 in cancer cells
}

\author{
PUMEI ZENG* ${ }^{*}$ YING WANG* ${ }^{*}$ YUTIAN ZHENG, XIAO SONG and YANHUI YIN \\ Department of Immunology, School of Basic Medical Sciences, Key Laboratory of Medical Immunology of Ministry of Health, \\ Peking University Health Science Center, Beijing 100191, P.R. China
}

Received June 21, 2017; Accepted October 20, 2017

DOI: $10.3892 / \mathrm{mmr} .2017 .8260$

\begin{abstract}
Hepatocellular carcinoma-associated antigen $587 /$ melanoma antigen gene (HCA587/MAGEC2) is a cancer-testis antigen, which is highly expressed in various types of tumors, but not in normal tissues with the exception of male germ-line cells. HCA587/MAGEC2 has been previously recognized as a tumor-specific target for immunotherapy; however, its biological functions have been relatively understudied. To investigate the function of HCA587/MAGEC2, the amino acid sequence of HCA587/MAGEC2 was analyzed by bioinformatics and it was demonstrated that HCA587/MAGEC2 contains a 9-amino acid transactivation domain which may mediate the interaction of most transcription factors with TATA-box binding protein associated factor 9 (TAF9), a general transcription coactivator. Co-immunoprecipitation experiments revealed that HCA587/MAGEC2 interacted with TAF9 in transfected 293T and in A375 melanoma cells endogenously expressing HCA587/MAGEC2, and confirmed the endogenous interaction of HCA587/MAGEC2 and TAF9 within cells. Endogenous HCA587/MAGEC2 and TAF9 were demonstrated to be co-localized principally in the nucleus of tumor cells using immunofluorescence. Glutathione-S-transferase pull-down experiments demonstrated that HCA587/MAGEC2 interacts with TAF9 directly and the conserved region in the TAF9 may becrucial for HCA587/MAGEC2 binding. The present study demonstrated that the cancer-testis antigen HCA587/MAGEC2 directly interacted with TAF9, which may provide novel information for identifying the oncogenic functions of HCA587/MAGEC2 in tumor cells.
\end{abstract}

Correspondence to: Dr Yanhui Yin, Department of Immunology, School of Basic Medical Sciences, Key Laboratory of Medical Immunology of Ministry of Health, Peking University Health Science Center, 38 Xue Yuan Road, Haidian, Beijing 100191, P.R. China

E-mail: yinyanhui@bjmu.edu.cn

${ }^{*}$ Contributed equally

Key words: cancer-testis antigen, hepatocellular carcinomaassociated antigen 587/melanoma antigen gene, TBP-associated factor 9 , interaction, tumor cell

\section{Introduction}

Hepatocellular carcinoma-associated antigen 587 (HCA587) was identified by serological analysis of a recombinant cDNA expression library from hepatocellular carcinoma (HCC) in our previous study (1) and the sequence of the HCA587 gene was identical to that of MAGEC2, a member of melanoma antigen gene (MAGE) family (2). The MAGE family of proteins is divided into two classes based on their expression pattern, the type I MAGEs include MAGEA, MAGEB and MAGEC protein subfamilies. The type I MAGE proteins are cancer-testis (CT) antigens and their expression is restricted to the undifferentiated spermatogenic cells or trophoblast lineage cells; however, they may be aberrantly expressed in various types of human cancer $(3,4)$. The type II MAGEs, such as MAGE-D, MAGE-E, MAGE-F and MAGE-G are expressed in various normal tissues (5). Type I and type II MAGE proteins share a conserved domain termed the MAGE homology domain (4).

Type I MAGE CT antigens have long been considered to be potential immunotherapy targets due to their restricted tissue expression (6-10) and the phase I/II trials of MAGE-based immunotherapy exhibited encouraging results (11-14). Previous studies have demonstrated that high MAGE expressions are associated with a poor clinical prognosis, increased tumor growth and metastases (15-19). It has been previously reported that the nuclear expression of MAGEC2 in prostate cancer is an independent predictor of recurrence following radical prostatectomy (20). In addition, multiple MAGE family proteins have been demonstrated to form complexes with certain RING domain proteins with specificity in cells, including MAGE-A2/C2-transcription intermediary factor $1-\beta$, MAGE-B18-ligand of numb protein $\mathrm{x} 1$ and MAGE-G1-non-structural maintenance of chromosomes element 1complexes (21). A recent study demonstrated that high expression of MAGEC2 in cancer cells is associated with amoeboid movement and increased tumor metastasis by interacting with signal transducer and activator of transcription 3 (STAT3) and inhibiting proteasomal degradation of tyrosine phosphorylated STAT3 (22). To further investigate the biological function of CT antigen HCA587/MAGEC2 within tumor cells, the amino acid sequence of HCA587/MAGEC2 was analyzed by bioinformatics and the results indicated that HCA587/MAGEC2 contains a 9-amino acid transactivation domain (9aa TAD), which is common to the transactivation domains of a number of 
diverse yeast and animal transcription factors. It has been previously reported that the majority of transcription factors (VP16, P53, heat shock factor protein 1 , nuclear factor- $\kappa \mathrm{B}$, NFAT1) interact with the general transcription coactivator TAF9 via the 9aa TAD $(23,24)$. Interaction of HCA587/MAGEC2 and TAF9 was demonstrated by co-immunoprecipitation and Glutathione-S-Transferase (GST) pull-down, and the conserved region $(\mathrm{CR})$ in the TAF9 was determined to be required for the interaction of HCA587/MAGEC2 with TAF9. Identification of HCA587/MAGEC2 protein interactions may further elucidate the function and regulation of HCA587/MAGEC2.

\section{Materials and methods}

Gene constructs. The cDNA encodings of HCA587/MAGEC2 and TAF9 were generated by reverse-transcription polymerase chain reaction (RT-PCR) using cDNA from A375 human malignant melanoma cells (ATCC, Manassas, VA, USA) as templates. Total RNA was isolated using TRIzol (Invitrogen; Thermo Fisher Scientific, Inc., Waltham, MA, USA), and first strand cDNA was generated using the Reverse Transcription kit (Promega Corporation, Madison, WI, USA). Primer sequences were forward, 5'-GCGTCGACGCCACCATGC CTCCCGTTCCAGGCGTT-3' and reverse, 5'-GAATGCGGC CGCTCACTCAGAAAAGGAGAC for HCA587/MAGEC2; forward, 5'-GCGTCGACAATGGAGTCTGGCAAGACG GCT-3' and reverse, 5'-ATAAGAATGCGGCCGCTTACA GATTATCATAGTCAT-3' for TAF9. The PCR conditions for both HCA587/MAGEC2 and TAF9 were $95^{\circ} \mathrm{C}$ for $5 \mathrm{~min}$, followed by 35 cycles at $95^{\circ} \mathrm{C}$ for $30 \mathrm{sec}, 58^{\circ} \mathrm{C}$ for $30 \mathrm{sec}$ and $72^{\circ} \mathrm{C}$ for $90 \mathrm{sec}$. The aforementioned cDNA was subcloned into expression vectors pRK-FLAG and/or pRK-hemagglutinin (HA) (provided by Professor Jun Zhang, Peking University), and the constructed plasmids were transfected into mammalian cells using Lipofectamine ${ }^{\circledR} 2000$ (Invitrogen; Thermo Fisher Scientific, Inc.) for expression of HCA587/MAGEC2 and TAF9 respectively. cDNA encoding TAF9 (residues 1-73), TAF9 (residues 74-147), TAF9 (residues 148-278) were generated by PCR (M3001; Promega Corporation) using TAF9 full-length cDNA plasmids as templates. Primer sequences were forward, 5'-GCGTCGACAGAGTCTGGCAAGACGGCTTCT-3' and reverse, 5'-ATAAGAATGCGGCCGCTCATGCCAATCGCA CATCATCT-3' for TAF9 (residues 1-73); forward, 5'-GCGTCG ACAATCCAGTGCCGCGCTGATCA-3' and reverse, ATA AGAATGCGGCCGCTCACCGCGGGACTGTTATTC for TAF9 (residues 74-147); forward, 5'-GCGTCGACATTAAGT GTTGGTTCAGTTAC-3' and reverse, 5'- ATAAGAATGCGG CCGCTTACAGATTATCATAGTCAT-3' for TAF9 (residues 148-278). The PCR conditions for all the fragments were $95^{\circ} \mathrm{C}$ for $5 \mathrm{~min}$, followed by 35 cycles at $95^{\circ} \mathrm{C}$ for $30 \mathrm{sec}, 60^{\circ} \mathrm{C}$ for $30 \mathrm{sec}$ and $72^{\circ} \mathrm{C}$ for $30 \mathrm{sec}$. For the glutathione S-transferase (GST)-fusion protein expression, cDNAs encoding full-length and truncated TAF9 were ligated into PGEX-4T vector (GE Healthcare, Chicago, IL, USA).

Co-immunoprecipitation and western blotting. 293T cells (ATCC) were maintained in Dulbecco's modified Eagle's medium (DMEM) supplemented with $10 \%$ fetal bovine serum (Invitrogen; Thermo Fisher Scientific, Inc.). The expression vectors pRK-FLAG-HCA587 and/or pRK-HA-TAF9
( $1 \mu \mathrm{g} / \mathrm{ml}$ respectively) were co-transfected into $293 \mathrm{~T}$ cells, using Lipofectamine 2000 (Invitrogen; Thermo Fisher Scientific, Inc.). The cells were harvested $48 \mathrm{~h}$ following transfection, washed with PBS, lysed with IP-buffer $(20 \mathrm{mM}$ Tris- $\mathrm{HCl}, 150 \mathrm{mM} \mathrm{NaCl}, 1 \%$ TritonX-100 and $1 \mathrm{mM}$ EDTA) supplemented with a protease inhibitors cocktail (Roche Diagnostics, Indianapolis, IN, USA), and the protein concentration of the cell extract was determined by BCA protein assay. Lysates were cleared by centrifugation at $16,000 \mathrm{x} \mathrm{g}$ for $10 \mathrm{~min}$ at $4^{\circ} \mathrm{C}$, pre-cleared with empty beads and subjected to immunoprecipitation with mouse monoclonal anti-HA antibody (M180-3; 1:2,000; MBL, Nagoya, Japan), mouse monoclonal anti-FLAG antibody (F1804; 1:5,000; Sigma-Aldrich; Merck KGaA, Darmstadt, Germany) or an equal amount of normal mouse immunoglobulin (Ig)G (I5381; Sigma-Aldrich; Merck KGaA) at $4^{\circ} \mathrm{C}$ overnight, followed by adding protein A-Sepharose (GE Healthcare) for additional $4 \mathrm{~h}$. For endogenous co-immunoprecipitation, A375 cells were lysed with IP-buffer and protein concentration was determined as described above, and subjected to immunoprecipitation with rabbit polyclonal anti-HCA587 antibody (TC-1; 1:200; 2 mg/ml prepared by our laboratory) (25) or normal rabbit IgG (I5006; 1:200; 2 mg/ml; Sigma-Aldrich; Merck KGaA). The immunoprecipitates were subsequently washed with IP-buffer for $1 \mathrm{~h}$ at $4^{\circ} \mathrm{C}$. Complexes were released from the protein-A-sepharose by boiling for $5 \mathrm{~min}$ in $2 \mathrm{X}$ SDS loading buffer, subjected to $10 \%$ SDS-PAGE (50 $\mu \mathrm{l}$ sample/lane), transferred to NC membranes, blocked with PBS-5\% skimmed milk at room temperature for $1 \mathrm{~h}$, and detected using anti-HA (M180-3; 1:2,000), anti-FLAG (F1804; 1:5,000), anti-HCA587 (McAb, LX-CT10.5; 1:1,000; provided by Professor Boquan Jin, Fourth Military Medical University) (26), or anti-TAF9 (ab169784; 1:1,000; Abcam, Cambridge, MA, USA) antibodies, followed by adding anti-mouse (W4021; 1:8,000; Promega Corporation) or anti-rabbit (W4011; 1:10,000; Promega Corporation) antibodies conjugated to horseradish peroxidase. Immunoreactive bands were analyzed with an enhanced chemiluminescence kit (BF06053; Beijing Biodragon Immunotechnologies Co., Ltd., Beijing, China.)

Immunofluorescence. A375 cells were grown directly on glass coverslips for $24 \mathrm{~h}$ and then fixed with $3.7 \%$ formaldehyde in PBS for $5 \mathrm{~min}$ at room temperature, and further permeabilized by $100 \%$ methanol for $5 \mathrm{~min}$ at $-20^{\circ} \mathrm{C}$. Following $1 \mathrm{~h}$ blocking in PBS-5\% skimmed milk at room temperature, cells were incubated overnight with the following antibodies: Anti-HCA587/MAGEC2 mouse IgG (LX-CT10.5; 1:500), anti-TAF9 rabbit IgG (sc98825; 1:100; Santa Cruz Biotechnology, Inc.), normal mouse IgG or normal rabbit IgG (equal amount of antibodies) were used as negative controls. Following washing with PBS, cells were incubated for $1 \mathrm{~h}$ at room temperature with FITC-conjugated anti-rabbit IgG or rhodamine-conjugated anti-mouse IgG (ZF0311 and ZF0313 respectively; 1:200; OriGene Technologies, Inc., Beijing, China). Hoechst 33342 (Sigma-Aldrich; Merck KGaA) staining was performed for $5 \mathrm{~min}$ at room temperature to visualize the cell nucleus. Images were captured and analyzed using a confocal microscope.

GSTpull-downassay. RecombinanthumanHCA587/MAGEC2 protein was prepared by Crown Bioscience, Inc., (Beijing, 


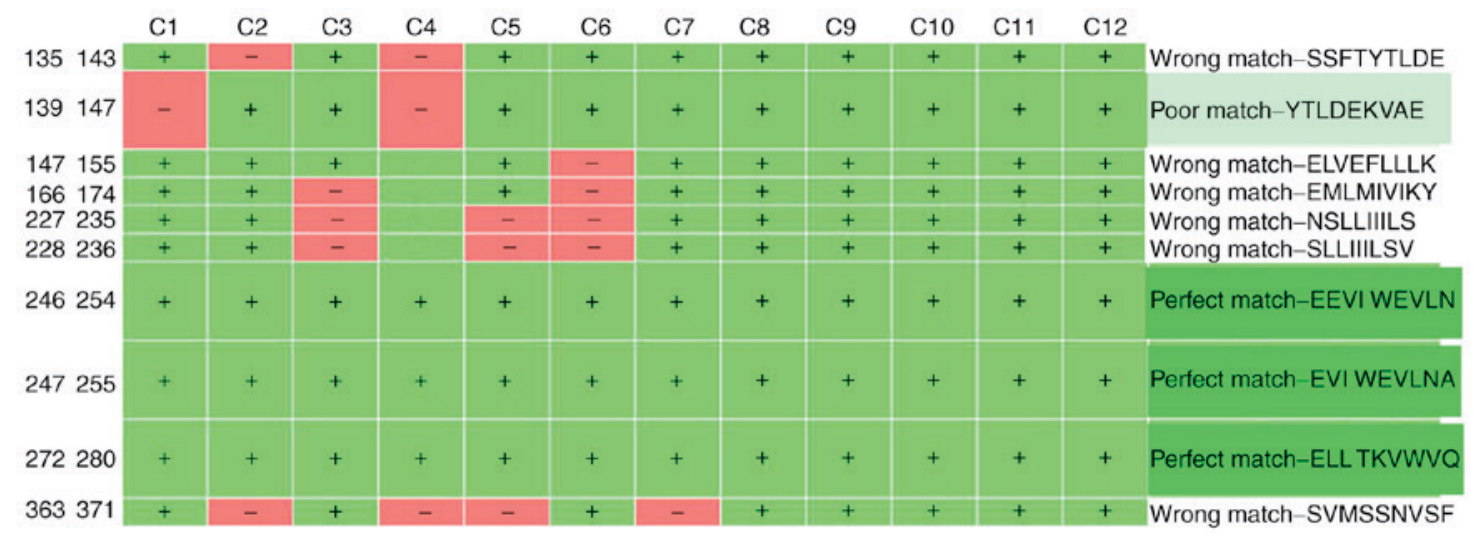

Figure 1. Identification of 9aa transactivation domain in hepatocellular carcinoma-associated antigen 587/melanoma antigen gene, C1-C12: Refinement criteria for 9 aa transactivation domain prediction (24). Amino acids of the same group are allowed as substitutions. aa, amino acids.

China) (27). GST-TAF9 (full-length), TAF9 (residues 1-73), TAF9 (residues 74-147) and TAF9 (residues 148-278) were expressed in bacterial host BL21(DE3) by induction with $1 \mathrm{mM}$ isopropyl-L-thio- $\beta$-D-galactopyranoside (Sigma-Aldrich; Merck KGaA), and were purified with glutathione Sepharose 4B beads (GE Healthcare) according to the instructions of the manufacturer. A total of $10 \mu \mathrm{g}$ glutathione Sepharose-linked GST or GST-fusion protein was incubated with the HCA587/MAGEC2 protein in $200 \mu \mathrm{l}$ GST binding buffer (PBS, 0.1\% NP-40, $5 \mathrm{mM}$ dithiothreitol and protease inhibitors cocktail) with rotation overnight at $4^{\circ} \mathrm{C}$. The beads were then washed for $1 \mathrm{~h}$ at $4^{\circ} \mathrm{C}$ and bound proteins were separated by $10 \%$ SDS-PAGE ( $30 \mu \mathrm{l}$ sample/lane), transferred to NC membranes, blocked with PBS-5\% skimmed milk at room temperature for $1 \mathrm{~h}$, and detected with anti-HCA587 (LX-CT10.5; 1:1,000), anti-GST $(1: 2,000 ; 10000-0$-AP; ProteinTech Group, Inc., Chicago, IL, USA), or anti-TAF9 (sc98825; 1:1,000; Santa Cruz Biotechnology, Inc.) antibodies, followed by adding anti-mouse or anti-rabbit antibodies conjugated to horseradish peroxidase (W4021 and W4011; Promega Corporation) at room temperature for $1 \mathrm{~h}$. Immunoreactive bands were analyzed with enhanced chemiluminescence kit as described above.

\section{Results}

HCA587/MAGEC2 contains a 9aa TAD. To determine the biological function of HCA587/MAGEC2, the aa sequence of HCA587/MAGEC2 was analyzed by bioinformatics. Based on the prediction algorithm provided by Piskacek et al (http://www.at.embnet.org/9aa) (24), the present study demonstrated that HCA587/MAGEC2 contains 3 perfectly matched 9aa TAD sequences which are located at aa 246-254, 247-255 and 272-280, respectively. The results of the 9aa TAD analysis are presented in Fig. 1.

Interaction of HCA587/MAGEC2 with TAF9 in transfected $293 T$ cells. Most proteins with a 9aa TAD are known to bind the general transcriptional cofactor TAF9. The presence of the 9aa TAD sequence in HCA587/MAGEC2 led to the investigation of whether HCA587/MAGEC2 interacts with TAF9. 293T cells were co-transfected with FLAG-tagged HCA587/MAGEC2 and HA-tagged TAF9, and the cellular

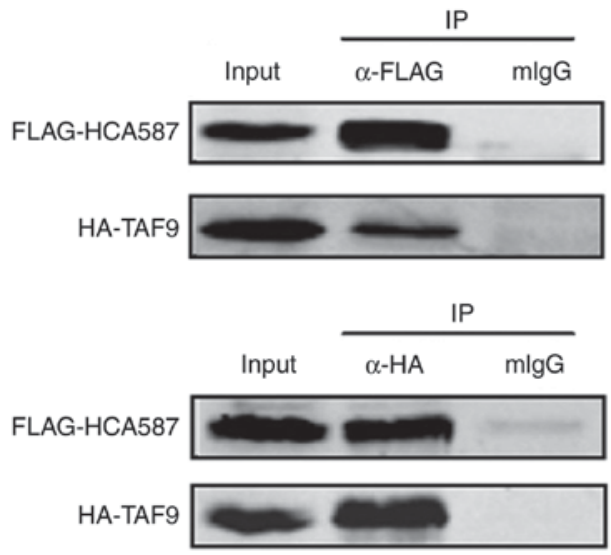

Figure 2. Co-immunoprecipitation assay for the interaction between HCA587/MAGEC2 and TAF9.Plasmids encoding FLAG-HCA587/MAGEC2 and HA-TAF9 proteins were co-transfected in 293T cells. The cell lysates are immunoprecipitated with anti-FLAG mAb, anti-HA mAb or mouse control IgG. The precipitates were analyzed by immunoblotting with anti-FLAG and anti-HA antibodies. The result demonstrated that overexpressed HCA587/MAGEC2 and TAF9 may interact with each other. Input corresponds to $10 \%$ of the total cell lysate. TAF9, TATA-box binding protein associated factor 9; HCA587/MAGEC2, hepatocellular carcinoma-associated antigen 587/melanoma antigen gene; mAb, monoclonal antibody; HA, hemagglutinin; $\mathrm{mIgG}$, mouse immunoglobulin $\mathrm{G}$.

lysates were immunoprecipitated with anti-FLAG or anti-HA monoclonal antibodies followed by immunoblotting with anti-HA or anti-FLAG antibodies. The results demonstrated that HCA587/MAGEC2 was co-immunoprecipitated with TAF9 (Fig. 2), suggesting that HCA587/MAGEC2 interacts with TAF9 in transfected 293T cells.

Subcellular co-localization of HCA587/MAGEC2 and TAF9. The subcellular co-localization of endogenous HCA587/MAGEC2 and TAF9 was examined in A375 human melanoma cell line expressing endogenous TAF9 and HCA587/MAGEC2 using double immunofluorescence staining. As presented in Fig. 3, HCA587/MAGEC2 and TAF9 were co-localized in the nucleus of A375 cells.

Interaction of HCA587/MAGEC2 and TAF9 in vivo. To confirm the endogenous interaction of HCA587/MAGEC2 with TAF9 within the tumor cells, a co-immunoprecipitation 

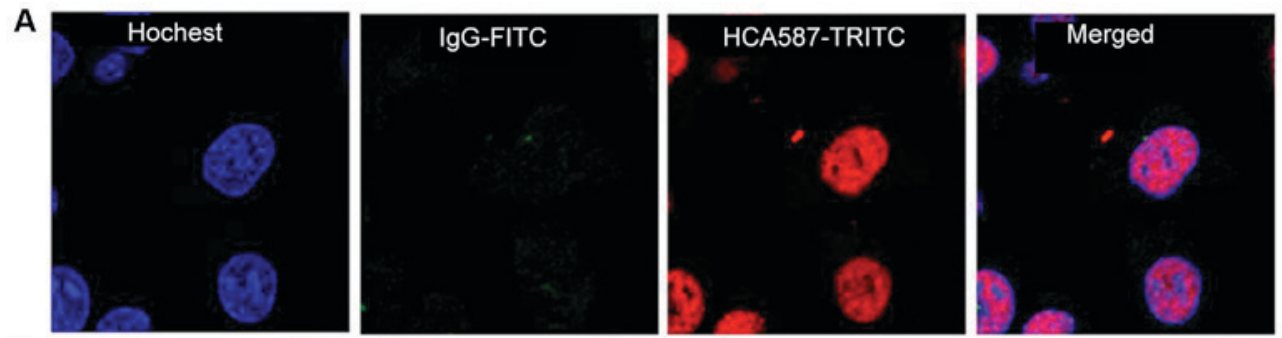

B
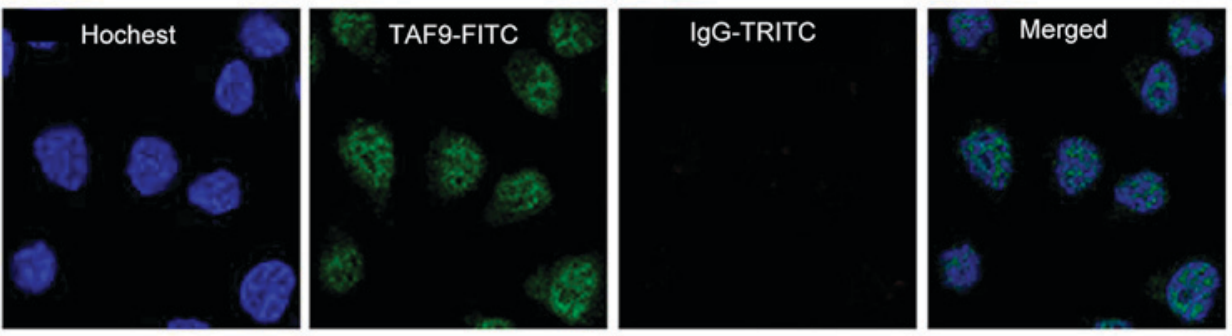

C
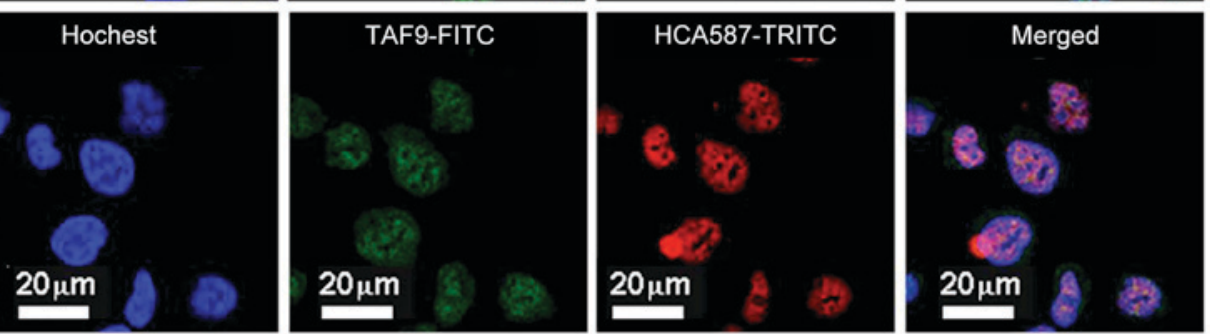

Figure 3. HCA587/MAGEC2 co-localizes with TAF9 to the nucleus of A375 cells. (A) The cellular distribution of endogenous HCA587/MAGEC2 in A375 cells detected by immunofluorescence using anti-HCA587 antibody. (B) The cellular distribution of endogenous TAF9 in A375 cells. (C) The cellular distribution of endogenous HCA587/MAGEC2 and TAF9 in A375 cells were analyzed using anti-HCA587/MAGEC2 and anti-TAF9 antibodies and visualized using FITC and TRITC labeled secondary antibodies, respectively. The merged image demonstrates the signals of anti-HCA587/MAGEC2 (red), anti-TAF9 (green) and Hoechst for DNA staining (blue) altogether. TAF9, TATA-box binding protein associated factor 9; HCA587/MAGEC2, hepatocellular carcinoma-associated antigen 587/melanoma antigen gene; TRITC, tetramethylrhodamine; FITC, fluorescein isothiocyanate; IgG, immunoglobulin G.

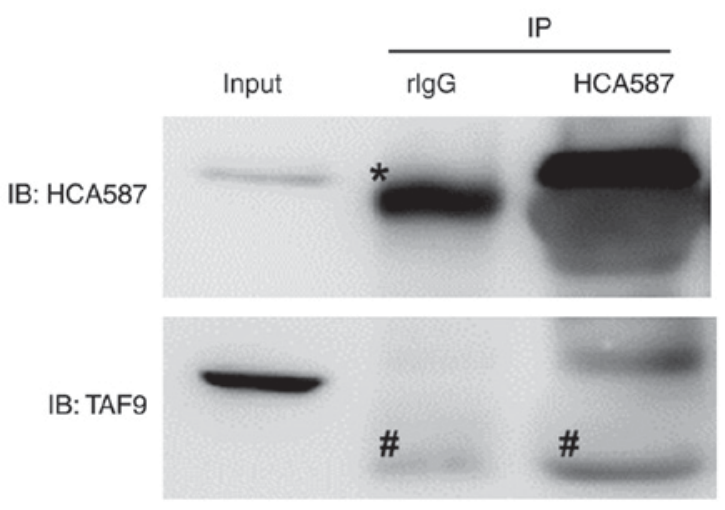

Figure 4. The endogenous interaction of HCA587/MAGEC2 with TAF9 in A 375 cells was detected by co-immunoprecipitation assay. Lysates from A375 cells were immunoprecipitated with anti-HCA587 antibody or control rabbit IgG followed by immunoblotting with anti-HCA587 or anti-TAF9 antibodies. "Indicates Ig heavy chain, ${ }^{*}$ indicates Ig light chain. Input corresponds to $10 \%$ of the total cell lysate. TAF9, TATA-box binding protein associated factor 9; HCA587/MAGEC2, hepatocellular carcinoma-associated antigen 587/melanoma antigen gene; rIgG, rabbit immunoglobulin G.

assay was performed in the A375 human melanoma cell line, which endogenously expresses HCA587/MAGEC2 and TAF9 molecules. Cellular lysates from A375 cells were immunoprecipitated with the anti-HCA587/MAGEC2 antibody and TAF9 was detected in HCA587/MAGEC2 immunoprecipitates (Fig. 4), indicating that endogenous HCA587/MAGEC2 interacts with endogenous TAF9 within tumor cells.

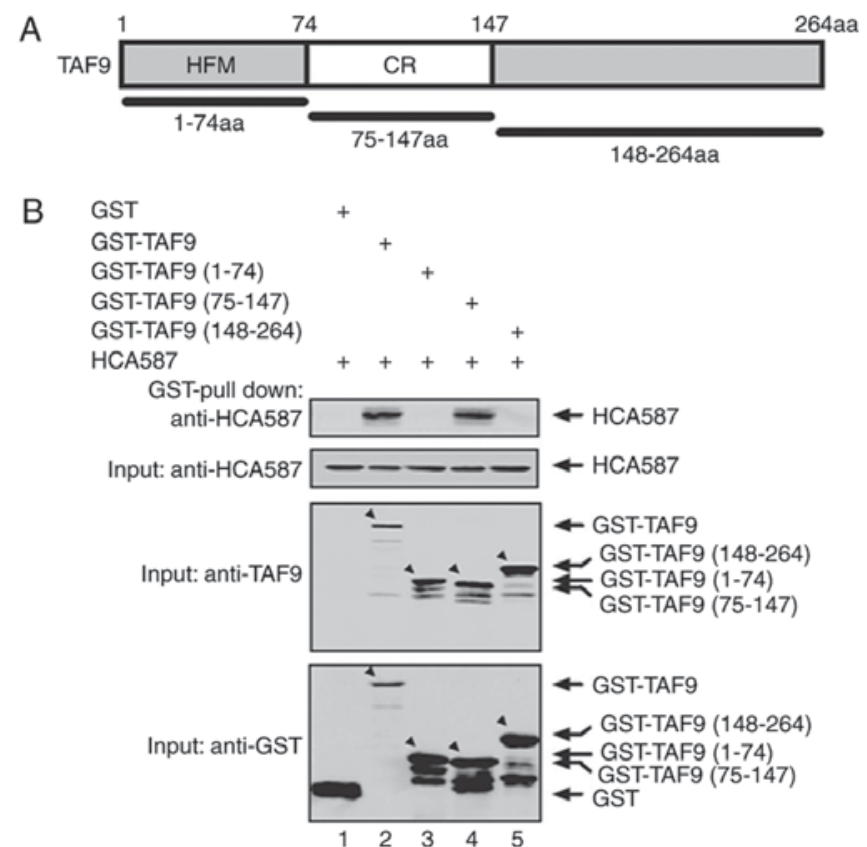

Figure 5. HCA587/MAGEC2 interacts with the CR domain of TAF9 in vitro. (A) Domain structure of the full-length TAF9. (B) GST pull-down assay demonstrated that HCA587/MAGEC2 bound specifically to full-length TAF9 and TAF9 CR (aa 75-147). Input lane represents $10 \%$ of the proteins used for the pulldown assay. The arrows indicate the band positions of TAF9 full-length and TAF9 truncated mutants. TAF9, TATA-box binding protein associated factor 9; HCA587/MAGEC2, hepatocellular carcinoma-associated antigen 587/melanoma antigen gene; GST, glutathione-S-transferase; CR, conserved region; aa, amino acids; HFM, histone fold homology. 
In vitro mapping of the interactive domains between HCA587/MAGEC2 and TAF9. In vitro GST pull-down assays were used to confirm the interaction between HCA587/MAGEC2 and TAF9, and to determine the respective interactive domains. To map the interactive domains of TAF9 responsible for its HCA587/MAGEC2 binding, a series of GST-TAF9 truncated mutants, the histone fold homology domain (HFD) GST-TAF9 (residues 1-74), the conserved region (CR) TAF9 (residues 75-147) and the C terminal region TAF9 (residues 148-278), were generated and used as bait in respective pull-down assays with HCA587/MAGEC2 (Fig. 5A). An interaction was observed between HCA587/MAGEC2 and TAF9 (full-length; Fig. 5B; lane 2); however, not with GST alone (Fig. 5B; lane 1). Only the CR of TAF9 [GST-TAF9(75-147)] was able to bind HCA587/MAGEC2 effectively (Fig. 5B; lane 4). GST-TAF9 (residues 1-74) and GST-TAF9 (residues 148-278) demonstrated no binding to HCA587/MAGEC2 (Fig. 5B; lanes 3 and 5). These results demonstrated that TAF9 directly binds HCA587/MAGEC2 through its CR domain.

\section{Discussion}

HCA587/MAGEC2 is a CT antigen expressed in a wide variety of malignancies, including hepatocellular carcinoma, melanoma, bladder cancer, head and neck cancer, breast cancer and lung cancer $(25,28)$. Previous studies focused primarily on identifying the potential of HCA587/MAGEC2 as a target for tumor immunotherapy. HCA587/MAGEC2 has been previously demonstrated to be immunogenic and induce spontaneous antibody and $\mathrm{T}$ cell immune responses in cancer patients with HCA587/MAGEC2-expressing tumors (28-30). To the best of our knowledge, 9 CTL and 4 Th epitopes have been identified by the present authors and others (30-32). Previous studies demonstrated that MAGEC2 expression in cancer cells correlated with their metastatic potential $(18,22,33,34)$.

In the present study, TAF9 was identified as a binding partner for HCA587/MAGEC2. TAF9 and HCA587/MAGEC2 were co-localized in the nucleus and were co-immunoprecipitated from transfected $293 \mathrm{~T}$ cells. In addition, the endogenous interaction of HCA587/MAGEC2 with TAF9 within the tumor cells was demonstrated by co-immunoprecipitation assay. TAF9 is a TATA-binding protein associated factor shared by two transcription co-activator complexes, TFIID and Spt-Ada-Gcn5-acetyltransferase (SAGA) complex (35). A genomic synthetic genetic array analysis using a temperature-sensitive allele of TAF9 indicated that TAF9 interacts genetically with $>100$ genes, including genes involved in the mediator complex, chromatin modification/remodeling complexes, regulators of transcription elongation and key genes for cell cycle control at the G1/S transition, as well as genes involved in cell polarity, cell integrity and protein synthesis (36). Synthetic interactions usually identify a functional connection between the genes involved. The genetic interactions of TAF9 revealed a significant functional association of TAF9 with regulators of transcription elongation, initiation, cell cycle progression and growth control. It was previously demonstrated by microarray analysis that TAF9 is required for the expression of $\sim 60 \%$ of the yeast genome (37). TAF9 is important because it is present in both
TFIID and SAGA and it is one of several histone-fold TAFs critical for the maintenance of the structural integrity of these complexes (38-40). However, the biological functions of TAF9 in tumorigenesis and development of cancer remain to be elucidated. Nault et al (41) reported that upregulated expression of TAF9 was associated with a poor prognosis for patients with hepatocellular carcinoma treated by resection. In addition, TAF9 was demonstrated to interact with Gli and regulated Gli activity, and treatment with an inhibitor that interferes with the Gli/TAF9 interaction suppresses tumor growth (42). In the present study, the binding of TAF9 with HCA587/MAGEC2 was demonstrated and HCA587/MAGEC2 was previously reported to promote tumor metastasis by binding with STAT3 (22); however, whether the interaction of TAF9 with HCA587/MAGEC2 is also associated with tumor metastasis requires further investigation.

TAF9 contains several domains: A highly conserved N-terminal HFD, important for interaction with the H4-like TAF6, another conserved region, with DNA binding activity and a long less-conserved C-terminal tail (43). The findings of the present study demonstrate that TAF9 directly binds HCA587/MAGEC2 through its CR domain, suggesting that HCA587/MAGEC2 may involve in TAF9 binding with DNA to regulate certain genes transcription.

The present study has provided considerable evidence that HCA587/MAGEC2 interacts with TAF9 in melanoma cells, further studies on the interaction between HCA587/MAGEC2 and TAF9 may potentially provide additional information on the role of HCA587/MAGEC2, or TAF9, in the development and progression of cancer.

\section{Acknowledgements}

The present study was supported by the National Natural Science Foundation of China (grant nos. 81671637 and 81472645).

\section{References}

1. Wang Y, Han KJ, Pang XW, Vaughan HA, Qu W, Dong XY, Peng JR, Zhao HT, Rui JA, Leng XS, et al: Large scale identification of human hepatocellular carcinoma-associated antigens by autoantibodies. J Immunol 169: 1102-1109, 2002.

2. Lucas S, De Plaen E and Boon T: MAGE-B5, MAGE-B6, MAGE-C2, and MAGE-C3: Four new members of the MAGE family with tumor-specific expression. Int J Cancer 87: 55-60, 2000.

3. Zendman AJ Ruiter DJ and Van Muijen GN: Cancer/testis-associated genes: Identification, expression profile, and putative function. J Cell Physiol 194: 272-288, 2003.

4. Chomez P, De Backer O, Bertrand M, De Plaen E, Boon T and Lucas S: An overview of the MAGE gene family with the identification of all human members of the family. Cancer Res 61: 5544-5551, 2001.

5. Barker PA and Salehi A: The MAGE proteins: Emerging roles in cell cycle progression, apoptosis, and neurogenetic disease. J Neurosci Res 67: 705-712, 2002.

6. Goodyear O, Agathanggelou A, Novitzky-Basso I, Siddique S, McSkeane T, Ryan G, Vyas P, Cavenagh J, Stankovic T, Moss $\mathrm{P}$ and Craddock C: Induction of a CD $8^{+} \mathrm{T}$-cell response to the MAGE cancer testis antigen by combined treatment with azacitidine and sodium valproate in patients with acute myeloid leukemia and myelodysplasia. Blood 116: 1908-1918, 2010.

7. Francois V, Ottaviani S, Renkvist N, Stockis J, Schuler G, Thielemans K, Colau D, Marchand M, Boon T, Lucas S and van der Bruggen P: The CD4(+) T-cell response of melanoma patients to a MAGE-A3 peptide vaccine involves potential regulatory T cells. Cancer Res 69: 4335-4345, 2009. 
8. Oehlrich N, Devitt G, Linnebacher M, Schwitalle Y, Grosskinski S, Stevanovic S and Zöller M: Generation of RAGE-1 and MAGE-9 peptide-specific cytotoxic T-lymphocyte lines for transfer in patients with renal cell carcinoma. Int J Cancer 117: 256-264, 2005

9. Tatsumi T, Kierstead LS, Ranieri E, Gesualdo L, Schena FP, Finke JH, Bukowski RM, Brusic V, Sidney J, Sette A, et al: MAGE-6 encodes HLA-DRbeta 1*0401-presented epitopes recognized by $\mathrm{CD}^{+} \mathrm{T}$ cells from patients with melanoma or renal cell carcinoma. Clin Cancer Res 9: 947-954, 2003.

10. Vansteenkiste J, Zielinski M, Linder A, Dahabreh J, Gonzalez EE, Malinowski W, Lopez-Brea M, Vanakesa T, Jassem J, Kalofonos H et al: Adjuvant MAGE-A3 immunotherapy in resected non-small-cell lung cancer: Phase II randomized study results. J Clin Oncol 31: 2396-2403, 2013.

11. Vantomme V, Dantinne C, Amrani N, Permanne P, Gheysen D, Bruck C, Stoter G, Britten CM, Keilholz U, Lamers CH, et al: Immunologic analysis of a phase I/II study of vaccination with MAGE-3 protein combined with the AS02B adjuvant in patients with MAGE-3-positive tumors. J Immunother 27: 124-135, 2004

12. van Baren N, Bonnet MC, Dréno B, Khammari A, Dorval T, Piperno-Neumann S, Liénard D, Speiser D, Marchand M, Brichard VG, et al: Tumoral and immunologic response after vaccination of melanoma patients with an ALVAC virus encoding MAGE antigens recognized by T cells. J Clin Oncol 23: 9008-9021, 2005.

13. Aleksić MM, Kapetanović V, Atanacković J, Jocić B and Zecević M: Simultaneous determination of cefotaxime and desacetylcefotaxime in real urine sample using voltammetric and high-performance liquid chromatographic methods. Talanta 77: 131-137, 2008

14. No authors listed: CD4 T-cell immunotherapy shows early promise. Cancer Discov 6: 567-568, 2016.

15. Hao J, Song X, Wang J, Guo C, Li Y, Li B, Zhang Y and Yin Y: Cancer-testis antigen MAGE-C2 binds Rbx1 and inhibits ubiquitin ligase-mediated turnover of cyclin E. Oncotarget 6 : 42028-42039, 2015.

16. Yang B, O'Herrin SM, Wu J, Reagan-Shaw S, Ma Y, Bhat KM, Gravekamp C, Setaluri V, Peters N, Hoffmann FM, et al: MAGE-A, mMage-b, and MAGE-C proteins form complexes with KAP1 and suppress p53-dependent apoptosis in MAGE-positive cell lines. Cancer Res 67: 9954-9962, 2007.

17. Ayyoub M, Scarlata CM, Hamai A, Pignon P and Valmori D Expression of MAGE-A3/6 in primary breast cancer is associated with hormone receptor negative status, high histologic grade, and poor survival. J Immunother 37: 73-76, 2014.

18. Yang F, Zhou X, Miao X, Zhang T, Hang X, Tie R, Liu N, Tian F, Wang F and Yuan J: MAGEC2, an epithelial-mesenchymal transition inducer, is associated with breast cancer metastasis. Breast Cancer Res Treat 145: 23-32, 2014.

19. Weon JL and Potts PR: The MAGE protein family and cancer. Curr Opin Cell Biol 37: 1-8, 2015.

20. von Boehmer L, Keller L, Mortezavi A, Provenzano M, Sais G, Hermanns T, Sulser T, Jungbluth AA, Old LJ, Kristiansen G, et al: MAGE-C2/CT10 protein expression is an independent predictor of recurrence in prostate cancer. PLoS One 6: e21366, 2011.

21. Doyle JM, Gao J, Wang J, Yang M and Potts PR: MAGE-RING protein complexes comprise a family of E3 ubiquitin ligases. Mol Cell 39: 963-974, 2010

22. Song X, Hao J, Wang J, Guo C, Wang Y, He Q, Tang H, Qin X, Li Y, Zhang Y and Yin Y: The cancer/testis antigen MAGEC2 promotes amoeboid invasion of tumor cells by enhancing STAT3 signaling. Oncogene 36: 1476-1486, 2017.

23. Uesugi M, Nyanguile $\mathrm{O}, \mathrm{Lu} \mathrm{H}$, Levine AJ and Verdine GL: Induced alpha helix in the VP16 activation domain upon binding to a human TAF. Science 277: 1310-1313, 1997.

24. Piskacek S, Gregor M, Nemethova M, Grabner M, Kovarik P and Piskacek M: Nine-amino-acid transactivation domain: Establishment and prediction utilities. Genomics 89: 756-768, 2007.

25. Li B, Qian XP, Pang XW, Zou WZ, Wang YP, Wu HY and Chen WF: HCA587 antigen expression in normal tissues and cancers: Correlation with tumor differentiation in hepatocellular carcinoma. Lab Invest 83: 1185-1192, 2003.
26. Zhuang R, Zhu Y, Fang L, Liu XS, Tian Y, Chen LH, Ouyang WM, $\mathrm{Xu} X \mathrm{XG}$, Jian JL, Güre AO, et al: Generation of monoclonal antibodies to cancer/testis (CT) antigen CT10/MAGE-C2. Cancer Immun 6: 7, 2006.

27. Chen J, Zhang L, Wen W, Hao J, Zeng P, Qian X, Zhang Y and Yin Y: Induction of HCA587-specific antitumor immunity with HCA587 protein formulated with $\mathrm{CpG}$ and ISCOM in mice. PLoS One 7: e47219, 2012.

28. Ma W, Germeau C, Vigneron N, Maernoudt AS, Morel S, Boon T, Coulie PG and Van den Eynde BJ: Two new tumor-specific antigenic peptides encoded by gene MAGE-C2 and presented to cytolytic T lymphocytes by HLA-A2. Int J Cancer 109: 698-702, 2004.

29. Li B, He X, Pang X, Zhang H, Chen J and Chen W: Elicitation of both CD4 and CD8 T-cell-mediated specific immune responses to HCA587 protein by autologous dendritic cells. Scand J Immunol 60: 506-513, 2004.

30. Ma W, Vigneron N, Chapiro J, Stroobant V, Germeau C, Boon T, Coulie PG and Van den Eynde BJ: A MAGE-C2 antigenic peptide processed by the immunoproteasome is recognized by cytolytic T cells isolated from a melanoma patient after successful immunotherapy. Int J Cancer 129: 2427-2434, 2011.

31. Xing Q, Pang XW, Peng JR, Yin YH,Li Y, Yu X, Zhou SP,Zhang Y and Chen WF: Identification of new cytotoxic T-lymphocyte epitopes from cancer testis antigen HCA587. Biochem Biophys Res Commun 372: 331-335, 2008

32. Wen W, Zhang L, Peng J, Chen J, Hao J, Li X, Qian X, Zeng P, Zhang $\mathrm{Y}$ and Yin Y: Identification of promiscuous HLA-DRrestricted $\mathrm{CD}^{+}{ }^{+} \mathrm{T}$-cell epitopes on the cancer-testis antigen HCA587. Cancer Sci 102: 1455-1461, 2011.

33. de Carvalho F, Costa ET, Camargo AA, Gregorio JC, Masotti C, Andrade VC, Strauss BE, Caballero OL, Atanackovic D and Colleoni GW: Targeting MAGE-C1/CT7 expression increases cell sensitivity to the proteasome inhibitor bortezomib in multiple myeloma cell lines. PLoS One 6: e27707, 2011.

34. Curioni-Fontecedro A, Nuber N, Mihic-Probst D, Seifert B, Soldini D, Dummer R, Knuth A, van den Broek M and Moch H: Expression of MAGE-C1/CT7 and MAGE-C2/CT10 predicts lymph node metastasis in melanoma patients. PLoS One 6: e21418, 2011

35. Grant PA, Schieltz D, Pray-Grant MG, Steger DJ, Reese JC, Yates JR III and Workman JL: A subset of TAF(II)s are integral components of the SAGA complex required for nucleosome acetylation and transcriptional stimulation. Cell 94: 45-53, 1998.

36. Milgrom E, West RW Jr, Gao $C$ and Shen WC: TFIID and Spt-Ada-Gen5-acetyltransferase functions probed by genome-wide synthetic genetic array analysis using a Saccharomyces cerevisiae taf9-ts allele. Genetics 171: 959-973,2005.

37. Shen WC, Bhaumik SR, Causton HC, Simon I, Zhu X, Jennings EG, Wang TH, Young RA and Green MR: Systematic analysis of essential yeast TAFs in genome-wide transcription and preinitiation complex assembly. EMBO J 22: 3395-3402, 2003.

38. Moqtaderi Z, Keaveney M and Struhl K: The histone H3-like TAF is broadly required for transcription in yeast. Mol Cell 2: 675-682, 1998

39. Wu PY, Ruhlmann C, Winston F and Schultz P: Molecular architecture of the S. Cerevisiae SAGA complex. Mol Cell 15: 199-208, 2004

40. Timmers HT and Tora L: SAGA unveiled. Trends Biochem Sci 30: 7-10, 2005

41. Nault JC, De Reyniès A, Villanueva A, Calderaro J, Rebouissou S, Couchy G, Decaens T, Franco D, Imbeaud S, Rousseau F, et al: A hepatocellular carcinoma 5-gene score associated with survival of patients after liver resection. Gastroenterology 145: 176-187, 2013.

42. Bosco-Clément G, Zhang F, Chen Z, Zhou HM, Li H, Mikami I, Hirata T, Yagui-Beltran A, Lui N, Do HT, et al: Targeting Gli transcription activation by small molecule suppresses tumor growth. Oncogene 33: 2087-2097, 2014

43. Shao H, Revach M, Moshonov S, Tzuman Y, Gazit K, Albeck S, Unger T and Dikstein R: Core promoter binding by histone-like TAF complexes. Mol Cell Biol 25: 206-219, 2005. 